\title{
Tracheal Stenosis Caused by Thoracic Malignancy: Correlation between CT-Based Tracheal Measurement and Spirometric Values before and after Tracheal Stenting
}

\author{
Shinya Azagami', Tsuneo Yamashiro's,3, Hiroshi Handa', Takeo Inoue1, Shin Matsuoka², \\ Teruomi Miyazawa1, Masamichi Mineshita ${ }^{1 *}$ \\ ${ }^{1}$ Division of Respiratory Medicine, Department of Internal Medicine, St. Marianna University School of Medicine, \\ Kawasaki City, Japan \\ ${ }^{2}$ Department of Radiology, St. Marianna University School of Medicine, Kawasaki City, Japan \\ ${ }^{3}$ Department of Radiology, Graduate School of Medical Science, University of the Ryukyus, Nishihara Town, Japan \\ Email: ^m-mine@marianna-u.ac.jp
}

How to cite this paper: Azagami, S., Yamashiro, T., Handa, H., Inoue, T., Matsuoka, S., Miyazawa, T. and Mineshita, M. (2017) Tracheal Stenosis Caused by Thoracic Malignancy: Correlation between CTBased Tracheal Measurement and Spirometric Values before and after Tracheal Stenting. Open Journal of Medical Imaging, 7, 6376.

https://doi.org/10.4236/ojmi.2017.73007

Received: July 1, 2017

Accepted: August 8, 2017

Published: August 11, 2017

Copyright (c) 2017 by authors and Scientific Research Publishing Inc. This work is licensed under the Creative Commons Attribution International License (CC BY 4.0).

http://creativecommons.org/licenses/by/4.0/ (c) (i) Open Access

\begin{abstract}
Background: The correlation between computed tomography (CT)-based tracheal size and spirometry values is unknown in patients with tracheal stenosis by thoracic malignancy, which is often treated by tracheal stenting. Objectives: To evaluate the correlation between the tracheal cross-sectional area (CSA) and spirometric values before and after tracheal stenting, and to confirm that greater improvement in tracheal CSA leads to a larger improvement in spirometry values. Methods: A total of 32 patients with malignant tracheal stenosis underwent tracheal stenting. Before $(n=32)$ and after $(n=27)$ treatment, patients underwent chest $\mathrm{CT}$, measuring mean and minimum tracheal CSA values, and spirometry. The correlation between tracheal CSA and each spirometric value was evaluated using Spearman rank correlation analysis. Differences in the pre- and posttreatment tracheal CSA and spirometric values were evaluated using the Wilcoxon matched-pairs test. Results: Significant improvement in the minimum tracheal CSA and in spirometric values was observed after stenting $(P<0.001)$. Pretreatment analysis revealed significant correlations between the minimum tracheal CSA and various spirometric values $(P<0.01)$, but posttreatment analysis showed weak or insignificant correlations. The increase in the minimum tracheal CSA obtained by stenting was significantly correlated with improvement in multiple spirometric values $(P<0.05)$. Conclusions: The tracheal size measured on chest CT correlates with patients' spirometric values, particularly at the prestenting examination,
\end{abstract}


in patients with malignant tracheal stenosis. The increase in the minimum tracheal CSA after stenting on CT is a predictor for improved spirometric values, which is first demonstrated by this study.

\section{Keywords}

Trachea, Lung Cancer, Tracheal Stent, Computed Tomography, Bronchoscopy

\section{Introduction}

Tracheal stenosis is often caused by thoracic malignancy, typically by direct tracheal invasion of primary cancers, external tracheal compression by lymph node metastases, and luminal narrowing by endoluminal tracheal malignancies. Malignant tracheal stenoses frequently cause dyspnea and asphyxia, resulting in high morbidity and mortality. It has been reported that more than $50 \%$ of patients with advanced-stage lung cancer have some extent of stenosis in the central airways [1]. A simulation analysis and a bronchoscopic study measuring intratracheal pressure showed that constriction of over $70 \%$ of the tracheal lumen causes severe airflow reduction [2] [3].

Although they are usually palliative treatments, bronchoscopic interventions have been developed for and used in symptomatic patients with malignant tracheal stenosis. Multiple studies have shown that tracheal stenting is very effective for the relief of symptoms and for prolonging survival [3]-[11]. Previous studies analyzing patients with central airway stenosis showed that stent placement at the flow-limiting point of the target airway provides significant improvement in pulmonary function and relief of symptoms [3] [8] [11]. Combining pulmonary function tests (PFTs), computed tomography (CT), and bronchoscopy, is considered beneficial in evaluating the severity of stenosis and the effect of tracheal stenting [3] [11]-[16].

While it has already been shown that statistically significant improvement in spirometric values is observed after intra-airway stenting for patients with malignant tracheobronchial stenoses [8], there is no previous analysis that evaluates the statistical correlation between quantitatively measured tracheal size and spirometric values in patients with malignant tracheal stenosis. However, these correlations have been noted in patients with relapsing polychondritis (RP). Usuba et al. clearly demonstrated that RP patients with more severe tracheal stenosis, as measured on chest CT, have worse spirometric values, particularly at end-expiration [17]. While it still is controversial whether small or collapsed proximal airways on chest CT are truly morbid in patients with chronic obstructive pulmonary disease (COPD) [18] [19] [20] [21], there are significant positive correlations between CT-based tracheal size and spirometric values in patients with RP [17]. 
Based on these observations, we hypothesize that there would also be significant correlations between tracheal size, as measured on chest CT, and spirometric values in patients with malignant tracheal stenosis. Further, we predict that enlargement of the trachea by stenting would correlate with improvement in spirometric values. The aim of our study is 1) to evaluate the correlation between the cross-sectional area (CSA) of the trachea on chest CT and spirometric values in patients with malignant tracheal stenosis, before and after tracheal stenting; 2) to evaluate the correlation between an increase in tracheal CSA after stenting and improvement in spirometric values.

\section{Materials and Methods}

This retrospective study was approved by the institutional review board at St. Marianna University School of Medicine, which waived the need for written informed consent.

\subsection{Subjects}

We reviewed the medical records and previous chest CT images of all patients who underwent implantation of a tracheal stent between April 2005 and April 2016. Forty-two patients were identified who had malignant tracheal stenosis and underwent tracheal stenting with pretreatment chest CT and PFT. All patients had severe tracheal stenosis caused by a malignant neoplasm and subjective symptoms related to the stenosis.

The exclusion criteria were severe stenosis and occlusion found at the main bronchus, not treated by tracheal stenting $(\mathrm{n}=7)$, and pretreatment chest CT performed at another institution $(\mathrm{n}=3)$. A total of 32 patients $(20$ men and 12 women, with a mean age of 63 years [range, 38 - 85 years]) were ultimately included in this study. The included patients had tracheal stenosis caused by lung cancer $(n=16)$, esophageal cancer $(n=6)$, thyroid cancer $(n=4)$, primary tracheal cancer $(n=1)$, laryngeal cancer $(n=1)$, and intratracheal or lymph node metastases from abdominal or pelvic cancer (rectal cancer, $\mathrm{n}=2$; uterine cervical cancer, $\mathrm{n}=1$; ureteral cancer, $\mathrm{n}=1$ ). Of the 32 patients, 27 underwent chest CT and PFT after stenting. The patient characteristics and PFT results are summarized in Table 1. Of the 32 patients, 26 (81\%) were current or previous smokers (10 current smokers and 16 previous smokers; mean smoking index, 32.7 packyears).

\subsection{CT Scanning}

All patients were scanned using a 64-row or 80-row detector CT scanners (Aquilion 64 or Aquilion PRIME; Toshiba Medical Systems, Otawara, Tochigi, Japan). Chest CT was performed in the supine position during breath hold at full inspiration. The scanning parameters were as follows: collimation, $0.5 \mathrm{~mm}$; tube voltage, $120 \mathrm{kVp}$; gantry rotation time, 0.5 seconds; beam pitch, 0.828 (Aquilion 64) or 0.813 (Aquilion PRIME). At pretreatment imaging using the Aquilion 64 
Table 1. Clinical characteristics and spirometric values.

\begin{tabular}{|c|c|c|c|c|c|}
\hline \multicolumn{6}{|l|}{ Patient characteristics } \\
\hline Sex (male:female) & $(20: 12)$ & & & & \\
\hline Age (years) & $63 \pm 13$ & $(38-85)$ & & & \\
\hline Height $(\mathrm{cm})$ & $162 \pm 10$ & $(144-179)$ & & & \\
\hline Weight (kg) & $52 \pm 11$ & $(35-80)$ & & & \\
\hline Spirometric value & \multicolumn{2}{|c|}{ Pretreatment $(\mathrm{n}=32)$} & \multicolumn{2}{|c|}{ Post treatment $(n=27)$} & $P$ value ${ }^{*}$ \\
\hline FVC (L) & $2.8 \pm 1.0$ & $(1.2-5.2)$ & $2.9 \pm 1.1$ & $(1.2-4.9)$ & NS \\
\hline $\mathrm{FEV}_{1}(\mathrm{~L})$ & $1.3 \pm 0.7$ & $(0.3-3.0)$ & $2.0 \pm 0.9$ & $(0.6-4.2)$ & $<0.0001$ \\
\hline $\mathrm{FEV}_{1} / \mathrm{FVC}$ & $0.55 \pm 0.22$ & $(0.11-0.93)$ & $0.71 \pm 0.11$ & $(47.2-85.8)$ & $<0.001$ \\
\hline $\mathrm{FEV}_{1}(\%$ predicted $)$ & $51.0 \pm 19.8$ & $(8.4-80.6)$ & $82.0 \pm 24.6$ & $(30.3-142)$ & $<0.0001$ \\
\hline $\mathrm{FEF}_{25-75 \%}(\mathrm{~L} / \mathrm{sec})$ & $1.24 \pm 0.8$ & $(0.2-3.1)$ & $2.10 \pm 1.29$ & $(0.15-5.98)$ & $<0.0001$ \\
\hline $\mathrm{FEF}_{25-75 \%}(\%$ predicted $)$ & $29.5 \pm 17.4$ & $(4.8-72.0)$ & $47.3 \pm 25.6$ & $(4.8-110.6)$ & $<0.0001$ \\
\hline Peak flow (L/sec) & $2.3 \pm 1.1$ & $(0.8-4.5)$ & $4.3 \pm 2.0$ & $(1.92-9.18)$ & $<0.0001$ \\
\hline
\end{tabular}

Abbreviations: SD, standard deviation; FVC, forced vital capacity; $\mathrm{FEV}_{1}$, forced expiratory volume in 1 second; $\mathrm{FEF}_{25-75 \%}$, forced expiratory flow at mid-expiratory phase; NS, not significant. ${ }^{*}$ Comparisons between pretreatment and posttreatment values were made using the Wilcoxon matched-pairs test for $27 \mathrm{pa}$ tients who had both pretreatment and posttreatment data. Note: continuous data are demonstrated as the mean \pm standard deviation (range).

machine, 17 patients were scanned using a fixed tube current setting of $200 \mathrm{~mA}$, and 8 patients were scanned using other fixed tube current settings (100 - 350 $\mathrm{mA})$. The tube current for the Aquilion PRIME scanner $(\mathrm{n}=7)$ was varied using automatic exposure control. At posttreatment imaging, the tube current setting for the Aquilion 64 scanner was fixed at $200 \mathrm{~mA}$ in 18 patients, and other settings were used in 5 patients $(100-150 \mathrm{~mA})$. As in pretreatment imaging, the tube current was varied during posttreatment imaging with the Aquilion PRIME scanner, using automatic exposure control $(n=4)$.

All images were reconstructed using a standard algorithm (FC04) with a slice thickness of $7 \mathrm{~mm}$. The imaging field of view was $320 \mathrm{~mm}$, and the pixel size was $0.625 \times 0.625 \mathrm{~mm}$.

A contrast medium was used for 6 patients at prestenting imaging and for 2 at poststenting imaging.

\subsection{CT Analysis: Measurement of Tracheal CSA}

Tracheal CSA measurement followed the methods used by a previous study, including the use of an open-source image-processing program (Image J, version 1.48; http://imagej.nih.gov/ij/) [17] [19]. A pulmonologist (S.A) with 5 years of experience in respiratory medicine performed the measurements, after being coached by an experienced radiologist familiar with the method (T.Y) with 15 years of experience in thoracic radiology). First, all axial CT images that included the intrathoracic trachea (from the top of the apex to the carina) were selected (between 9 and 11 images, depending on the patient's body habitus). 
Second, the tracheal lumen on each image was extracted from the surrounding structures using a semiautomatic threshold technique (between -500 and -1024 Hounsfield Units [HU]). Finally, the extracted tracheal lumen was measured as the tracheal CSA on all selected images, and the mean and minimum tracheal CSAs were obtained. These measurement processes were applied to both pretreatment and posttreatment scans.

\subsection{CT Analysis: Measurement of Emphysema}

As an index for the extent of pulmonary emphysema, the low attenuation area percentage (LAA\%) was automatically measured using open-source software (Airway Inspector; Boston, MA; http://airwayinspector.acil-bwh.org/) [19]. In brief, the software segmented the lung parenchyma (between -500 and -1024 $\mathrm{HU}$ ) from the chest wall and the hilum, created a density histogram of the lung parenchyma, and measured LAA\% (<-950 HU). The LAA\% measurements were performed using the prestenting CT unless that scan was enhanced. For the 6 patients whose prestenting CT scans were enhanced, the poststenting scans without contrast were analyzed instead. Thus, LAA\% was measured using plain CT data in all patients.

\subsection{Pulmonary Function Testing}

All 32 subjects performed pretreatment spirometry within 2 weeks of the pretreatment CT. After stenting, 27 patients underwent posttreatment spirometry within 2 weeks of the posttreatment CT. Spirometry was performed according to the protocol of the European Respiratory Society [22]. The measurements included forced vital capacity (FVC), forced expiratory volume in 1 second $\left(\mathrm{FEV}_{1}\right)$, forced expiratory flow at the mid-expiratory phase $\left(\mathrm{FEF}_{25-75 \%}\right)$, and peak flow (PEF). The ratio of $\mathrm{FEV}_{1}$ to $\mathrm{FVC}$ was calculated $\left(\mathrm{FEV}_{1} / \mathrm{FVC}\right)$. Values for $\mathrm{FEV}_{1}$ and $\mathrm{FEF}_{25-75 \%}$ were also expressed as percentages of predicted values. The results of spirometry are summarized in Table 1.

\subsection{Tracheal Stenting}

All subjects were intubated using a rigid bronchoscope (EFER-Dumon; EFER Medical, La Ciotat, France) under general anesthesia. A total of 17 patients received a Spiral Z stent (Medico's Hirata, Inc., Osaka, Japan), 6 received an Ultraflex stent (Boston Scientific, Marlborough, MA, USA), 5 received a Tracheobronxane-Dumon stent (Novatech, Grasse, France), 1 received a TM stent (Fuji systems, Tokyo, Japan) and 3 received an AERO stent (Merit Medical Endotek, South Jordan, UT, USA).

The Spiral Z stent, an improved model of the Gianturco Z stent (Cook Medical, Inc., Bloomington, IN, USA), was a continuous loop stent of stainless steel wire; this stent was uncovered and self-expanding. The Ultraflex stent was a self-expanding, metallic stent made of nitinol; this stent had both covered and uncovered types. The Tracheobronxane-Dumon stent and TM stent were sili- 
cone stents for central airway stenosis; it could be customized for length, shape, and diameter, and as a fully covered stent, was not self-expanding. The AERO stent was a hybrid stent that consisted of a covered piece of nitinol. Hybrid airway stents were designed to remedy the drawbacks of conventional silicone or metallic stents. This stent was fully covered and self-expanding. The selection of stent at time of bronchoscopic intervention was made by the interventional pulmonologists, based on the bronchoscopic appearance of severity and stenosis.

\subsection{Statistical Analysis}

The correlation of tracheal CSA measurements or LAA\% measurements with spirometric values was determined using Spearman rank correlation analysis. The differences in values between pre- and poststenting spirometry and tracheal CSA were judged using the Wilcoxon matched-pairs test. All statistical analyses were performed using JMP software, version 12.0 (SAS Institute, Cary, NC). Continuous data were expressed as the mean \pm standard deviation. For all statistical analyses, a $P$ value of less than 0.05 was considered statistically significant.

\section{Results}

\subsection{Pulmonary Function Testing}

The mean values of all spirometric values, except for the FVC, increased from prestenting to poststenting examination. For the 27 patients with poststentingspirometric data available, significant increases in $\mathrm{FEV}_{1}, \mathrm{FEV}_{1} / \mathrm{FVC}, \mathrm{FEF}_{25-75 \%}$, and PEF values were confirmed after tracheal stenting $(P<0.001)$ (Table 1$)$.

\subsection{Tracheal Measurement}

The minimum tracheal CSA was $40.5 \pm 18.2 \mathrm{~mm}^{2}$ before stenting $(\mathrm{n}=32)$ and $86.8 \pm 40.5 \mathrm{~mm}^{2}$ after stenting $(\mathrm{n}=27)$, while the mean tracheal CSA was $154.4 \pm$ $60.7 \mathrm{~mm}^{2}$ before stenting $(\mathrm{n}=32)$ and $151.7 \pm 49.6 \mathrm{~mm}^{2}$ after stenting $(\mathrm{n}=27)$. For 27 patients with poststenting data available, a significant increase in the minimum tracheal CSA was confirmed after stenting $(P<0.0001)$.

\subsection{Correlation between Tracheal Measurement and Spirometric Values before Stenting $(n=32)$}

The pretreatment tracheal CSA measurements and their correlations with spirometric values are given in Table 2. The minimum tracheal CSA was significantly and positively correlated with the $\mathrm{FEV}_{1}, \mathrm{FEV}_{1} / \mathrm{FVC}, \mathrm{FEF}_{25-75 \%}$, and PEF values ( $\rho=0.485-0.556, P<0.01$ ), suggesting that tracheal luminal narrowing is a significant predictor of airflow limitation. Particularly strong correlations were found with $\mathrm{FEV}_{1}$ and PEF values ( $\mathrm{FEV}_{1}, \rho=0.770$; PEF, $\rho=0.748 ; P<0.0001$ for both, Figure 1). The mean tracheal CSA was not correlated with spirometric values, except for weak correlations with $\mathrm{FEV}_{1}$ and PEF values $(P<0.05)$ (Table 2 ). These data suggest that the most stenotic point of the trachea is the most powerful inhibitor for obstructive conditions. 
Table 2. Pretreatment tracheal cross-sectional area and correlation with pretreatment spirometry $(\mathrm{n}=32)$.

\begin{tabular}{|c|c|c|c|c|c|c|}
\hline \multirow[t]{2}{*}{ CT measurement } & \multicolumn{6}{|c|}{ Correlation coefficient $(\rho)$ for spirometric measurement } \\
\hline & $\mathrm{FEV}_{1}$ & $\begin{array}{c}\mathrm{FEV}_{1} \\
\text { (\%predicted) }\end{array}$ & $\mathrm{FEV}_{1} / \mathrm{FVC}$ & $\mathrm{FEF}_{25-75 \%}$ & $\begin{array}{c}\mathrm{FEF}_{25-75 \%} \\
\text { (\%predicted) }\end{array}$ & Peak flow \\
\hline Mean tracheal CSA & $\begin{array}{c}0.388 \\
(P<0.05)\end{array}$ & $\begin{array}{l}0.110 \\
(\mathrm{NS})\end{array}$ & $\begin{array}{l}0.211 \\
(\mathrm{NS})\end{array}$ & $\begin{array}{l}0.255 \\
\text { (NS) }\end{array}$ & $\begin{array}{l}0.145 \\
(\mathrm{NS})\end{array}$ & $\begin{array}{c}0.358 \\
(P<0.05)\end{array}$ \\
\hline Minimum tracheal CSA & $\begin{array}{c}0.770 \\
(P<0.0001)\end{array}$ & $\begin{array}{c}0.485 \\
(P<0.01)\end{array}$ & $\begin{array}{c}0.490 \\
(P<0.01)\end{array}$ & $\begin{array}{c}0.635 \\
(P<0.0001)\end{array}$ & $\begin{array}{c}0.556 \\
(P<0.01)\end{array}$ & $\begin{array}{c}0.748 \\
(P<0.0001)\end{array}$ \\
\hline LAA\% & $\begin{array}{c}-0.164 \\
(\mathrm{NS})\end{array}$ & $\begin{array}{c}-0.172 \\
(\mathrm{NS})\end{array}$ & $\begin{array}{c}-0.260 \\
(\mathrm{NS})\end{array}$ & $\begin{array}{c}-0.234 \\
(\mathrm{NS})\end{array}$ & $\begin{array}{c}-0.260 \\
(\mathrm{NS})\end{array}$ & $\begin{array}{c}-0.080 \\
(\mathrm{NS})\end{array}$ \\
\hline
\end{tabular}

Abbreviations: CT, computed tomography; CSA, cross-sectional area; LAA\%, low attenuation area percentage; $\mathrm{FEV}_{1}$, forced expiratory volume in 1 second; FVC, forced vital capacity; $\mathrm{FEF}_{25-75 \%}$, forced expiratory flow at mid-expiratory phase; NS, not significant.

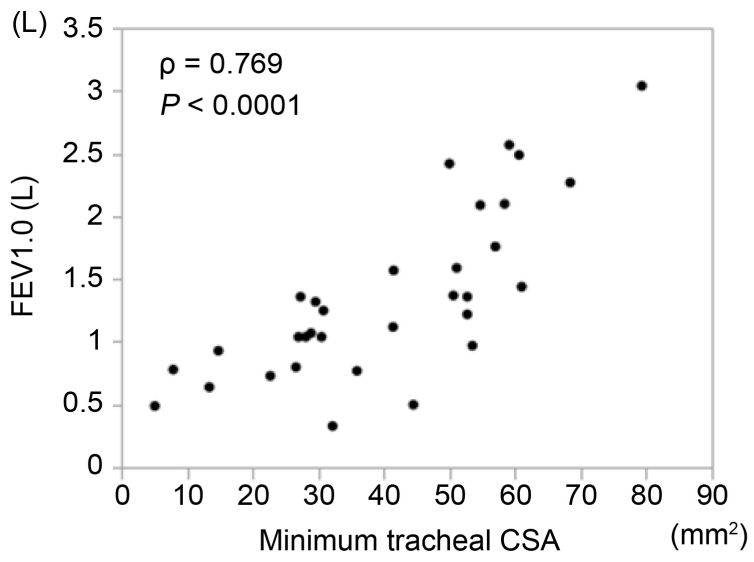

(a)

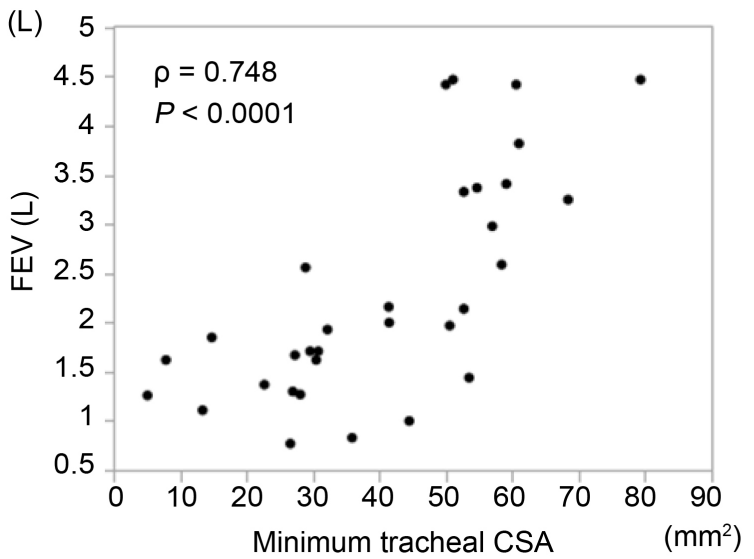

(c)

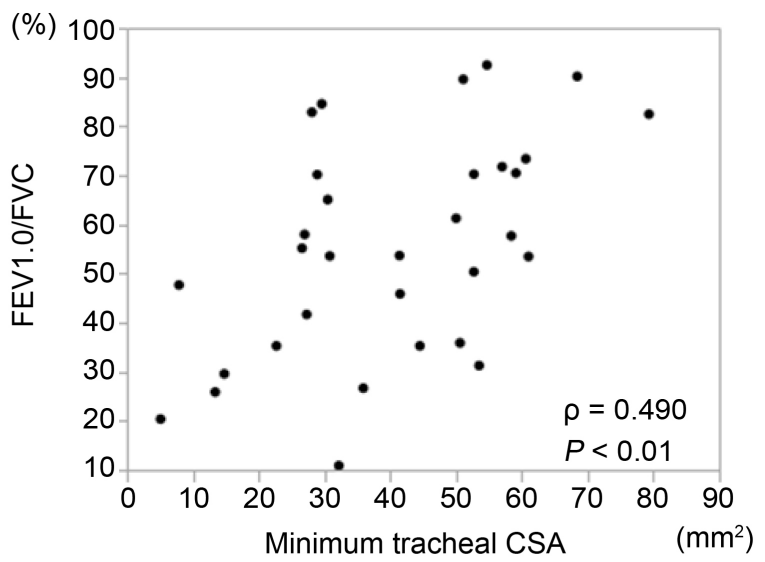

(b)

Figure 1. Correlations between the prestenting minimum tracheal cross-sectional area (CSA) and spirometric values. Significant correlations are confirmed with all spirometric values ((a), FEV1; (b), FEV 1.0 /FVC; (c), peak flow, respectively).

\subsection{Correlation between Tracheal Measurement and Spirometric Values after Stenting $(n=27)$}

The posttreatment tracheal CSA measurements and their correlations with spirometric values are given in Table 3 . In contrast to the prestenting results, the minimum tracheal CSA showed a weak correlation with $\mathrm{FEV}_{1}$ and $\mathrm{PEF}$ values 
only $(P<0.05)$. A similarly weak correlation between the mean tracheal CSA and these spirometric values was noted (Table 3 ). Although there were some tendencies toward a positive relation between the tracheal CSA and other spirometric values, they were not statistically significant.

\subsection{Correlation between Increase in Tracheal Size and Improvement in Spirometric Values}

Table 4 shows the correlations between the differences in tracheal size and the differences in spirometric values, comparing prestenting with poststenting data $(n=27)$. Significant positive correlations were found between the increase in the minimum tracheal CSA and the improvements in some spirometric values $\left(\mathrm{FEV}_{1}, \mathrm{FEV}_{1} \%\right.$ predicted, $\mathrm{FEV}_{1} / \mathrm{FVC}$, and PEF; $\left.\rho=0.397-0.594 ; P<0.05\right)$. These observations suggest that the more expanded trachea created by the stent resulted in a larger improvement in PFT values (Figure 2 and Figure 3).

Table 3. Posttreatment tracheal cross-sectional area and correlation with posttreatment spirometry $(n=27)$.

\begin{tabular}{ccccccc}
\hline CT measurement & \multicolumn{5}{c}{ Correlation coefficient $(\rho)$ for spirometric value } \\
& $\mathrm{FEV}_{1}$ & $\begin{array}{c}\mathrm{FEV}_{1} \\
(\% \text { predicted })\end{array}$ & $\mathrm{FEV}_{1} / \mathrm{FVC}$ & $\mathrm{FEF}_{25-75 \%}$ & $\begin{array}{c}\mathrm{FEF}_{25-75 \%} \\
(\% \text { predicted })\end{array}$ & Peak flow \\
\hline Mean tracheal & 0.469 & 0.312 & 0.044 & 0.266 & 0.176 & 0.410 \\
CSA & $(P<0.05)$ & $(\mathrm{NS})$ & $(\mathrm{NS})$ & $(\mathrm{NS})$ & $(\mathrm{NS})$ & $(P<0.05)$ \\
Minimum & 0.435 & 0.289 & 0.333 & 0.259 & 0.228 & 0.578 \\
tracheal CSA & $(P<0.05)$ & $(\mathrm{NS})$ & $(\mathrm{NS})$ & $(\mathrm{NS})$ & $(\mathrm{NS})$ & $(P<0.01)$ \\
& & & & & & \\
LAA\% & -0.195 & -0.319 & -0.196 & -0.306 & -0.350 & -0.119 \\
& $(\mathrm{NS})$ & $(\mathrm{NS})$ & $(\mathrm{NS})$ & $(\mathrm{NS})$ & $(\mathrm{NS})$ & $(\mathrm{NS})$ \\
\hline
\end{tabular}

Abbreviations: CT, computed tomography; CSA, cross-sectional area; LAA\%, low attenuation area percentage; $\mathrm{FEV}_{1}$, forced expiratory volume in 1 second; $\mathrm{FVC}$, forced vital capacity; $\mathrm{FEF}_{25-75 \%}$, forced expiratory flow at mid-expiratory phase; NS, not significant.

Table 4. Correlation between the difference in the minimum tracheal cross-sectional area and the differences in spirometric values, comparing pretreatment with posttreatment data $(n=27)$.

\begin{tabular}{|c|c|c|c|c|c|c|}
\hline \multirow{2}{*}{$\begin{array}{c}\text { Tracheal } \\
\text { measurement }\end{array}$} & \multicolumn{6}{|c|}{ Correlation coefficient $(\rho)$ for differences in spirometric values* } \\
\hline & $\mathrm{FEV}_{1}$ & $\begin{array}{c}\mathrm{FEV}_{1} \\
\text { (\% predicted) }\end{array}$ & $\mathrm{FEV}_{1} / \mathrm{FVC}$ & $\mathrm{FEF}_{25-75 \%}$ & $\begin{array}{c}\mathrm{FEF}_{25-75 \%} \\
\text { (\% predicted) }\end{array}$ & Peak flow \\
\hline $\begin{array}{c}\text { Difference in } \\
\text { minimumtracheal } \\
\text { CSA }^{*}\end{array}$ & $\begin{array}{c}0.446 \\
(P<0.05)\end{array}$ & $\begin{array}{c}0.418 \\
(P<0.05)\end{array}$ & $\begin{array}{c}0.594 \\
(P<0.01)\end{array}$ & $\begin{array}{l}0.240 \\
(\mathrm{NS})\end{array}$ & $\begin{array}{l}0.250 \\
(\mathrm{NS})\end{array}$ & $\begin{array}{c}0.397 \\
(P<0.05)\end{array}$ \\
\hline $\begin{array}{l}\text { Abbreviations: CSA, } \\
\text { volume in } 1 \text { second; } \\
\text { NS, not significant. } \\
\text { value minus the pret }\end{array}$ & $\begin{array}{l}\text { cross-section } \\
\text { FVC, forced } \\
\text { Differences ir } \\
\text { eatment valu }\end{array}$ & $\begin{array}{l}1 \text { area; LAA\%, lc } \\
\text { vital capacity; FE } \\
\text { tracheal CSA ar }\end{array}$ & $\begin{array}{l}\text { ow attenuatio } \\
\mathrm{EF}_{25-75 \%} \text {, force } \\
\text { nd spirometri }\end{array}$ & $\begin{array}{l}\text { area perce } \\
\text { expiratory } \\
\text { values wer }\end{array}$ & $\begin{array}{l}\text { tage; } \mathrm{FEV}_{1} \text {, forc } \\
\text { low at mid-expi } \\
\text { defined as the } \mathrm{F}\end{array}$ & $\begin{array}{l}\text { ed expiratory } \\
\text { ratory phase } \\
\text { osttreatmen }\end{array}$ \\
\hline
\end{tabular}




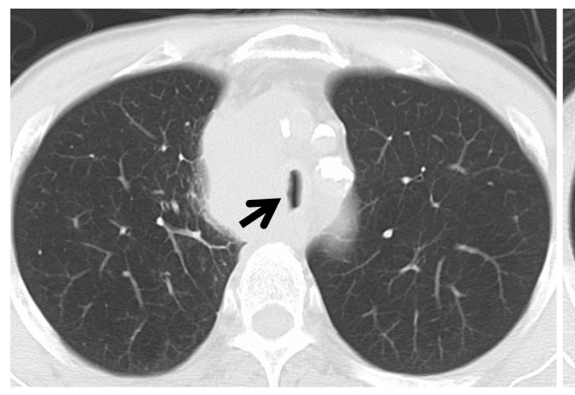

(a)

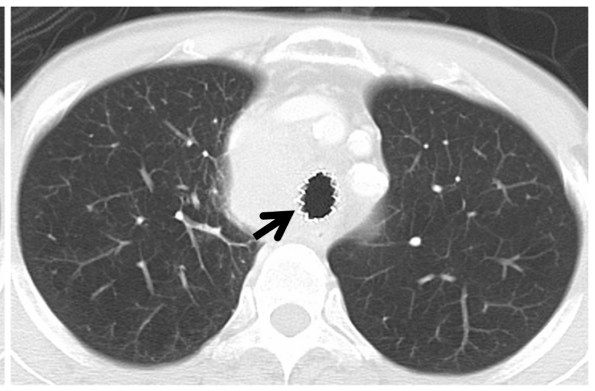

(b)

Figure 2. 54-year-old man with tracheal stenosis caused by primary lung cancer (adenocarcinoma). Prestenting computed tomography (a) demonstrates severe tracheal stenosis, relieved by tracheal stenting (b) (arrows). The forced expiratory volume in 1 second $\left(\mathrm{FEV}_{1}\right)$ increased from 0.97 to $2.86 \mathrm{~L}$, and the peak flow increased from 1.44 to $5.01 \mathrm{~L} / \mathrm{sec}$ after stenting.

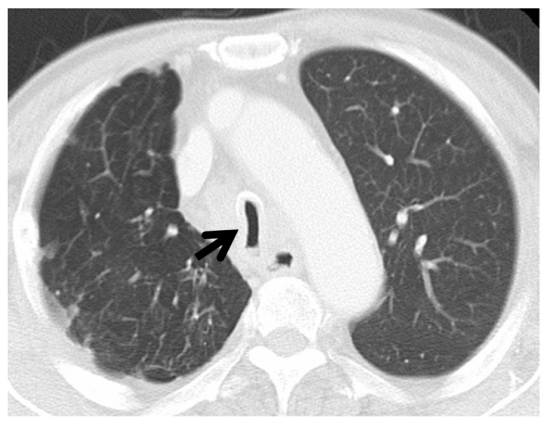

(a)

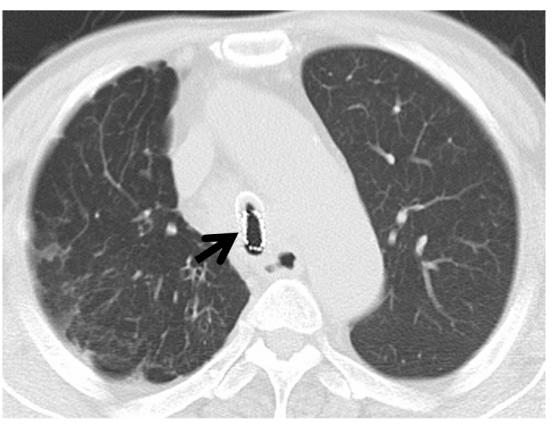

(b)

Figure 3. 58-year-old man with tracheal stenosis caused by primary lung cancer (adenocarcinoma). Severe tracheal stenosis before stenting (a) is not fully resolved by tracheal stenting (b) (arrows). The $\mathrm{FEV}_{1}$ increased slightly, from 1.36 to $1.8 \mathrm{~L}$, and the peak flow increased from 2.14 to $2.64 \mathrm{~L} / \mathrm{sec}$ after stenting.

\subsection{Emphysema Measurement Had No Correlation to Spirometric Values}

The mean LAA $\%$ was $2.2 \% \pm 4.5 \%$ (range, $0 \%-18.7 \%$ ). No correlation was observed between LAA $\%$ and prestenting or poststenting spirometric values (Table 2 and Table 3). Thus, in this study population, we determined that the influence of tracheal stenosis was more important for airflow limitation than the presence of either emphysema or COPD. Interestingly, all correlation coefficients with various spirometric values were larger at poststenting than at prestenting examination, which may imply that the effect of emphysema on airflow limitation is increased after tracheal stenosis is relieved by stenting.

\section{Discussion}

We demonstrated that 1) CT-based tracheal CSA measurements, particularly the minimum tracheal CSA before stenting, are significantly correlated with spirometric values in patients with malignant tracheal stenosis; and 2) the increase in the minimum tracheal CSA created by stenting is also significantly correlated 
with improvements in spirometric values. These novel observations can be applied to future clinical care for malignant tracheal stenosis, either in determining the utility of tracheal stenting or in evaluating the effect of the implanted stent.

Tracheal stenosis and abnormal tracheal collapse are caused by several different conditions such as tracheomalacia (excessive dynamic airway collapse), RP, and thoracic malignancy. It is already known that the choke-point (the most narrowed point) of the central airway is responsible for airflow limitation and the patient's symptoms; this choke-point is usually identified by bronchoscopy, chest CT, or impulse oscillometry [17] [23] [24]. However, it is still unclear whether the severity of tracheal stenosis is correlated with the severity of airflow limitation, and no published information is available regarding quantitative airway analysis based on chest CT in patients with malignant tracheal stenosis. Ours is the first study to demonstrate quantitative airway analyses of malignant tracheal stenosis and its correlation with spirometric values. Similar to the results seen in RP patients [17], the minimum tracheal CSA on CT is significantly positively correlated with spirometric values in patients with malignant bronchial stenosis. Further, the significant correlation between the increase in the minimum tracheal CSA created by stenting and the improvement in spirometric values suggests that the degree of expansion at the most stenotic point of the trachea is directly related to the positive effect of tracheal stenting. Our observations and approaches could be expanded to other conditions that cause central airway stenosis.

In patients with malignant tracheal stenosis, the degree of stenosis or deterioration of stenosis is usually monitored using PFT, particularly spirometry. Spirometry is a noninvasive, convenient examination that does not require largescale equipment or a power source. Thus, in many institutions, spirometry is the first-choice examination for evaluating central airway diseases. Compared with spirometry, chest CT is a relatively high-cost examination; although it is minimally invasive, it does result in some radiation exposure. Repeated CT examinations within a short period should therefore be avoided, and the need for chest CT should be determined carefully by evaluating the spirometric findings and the patient's symptoms. However, chest CT is a very powerful clinical examination tool since it can provide the most objective information on the stenotic trachea. Even in the early stages of malignant tracheal stenosis, the combination of spirometry and chest CT reveals progressive stenosis of the central airways, which can be a clinical biomarker for tracheal stent application. Further, if the tracheal stenosis progresses rapidly and the patient suffers from severe dyspnea, spirometry cannot be performed correctly and the resulting data are unreliable. In such a situation, as is shown in our study, chest CT can be used as an alternative to spirometry to provide objective analysis; CT can be a good indicator of progression or severity of tracheal stenosis. We therefore recommend that the choice to use either spirometry, chest CT, or both should be based on each patient's condition. The appropriate use of chest CT provides important, objective 
information to clinicians regarding the progression of tracheal stenosis and the utility of tracheal stenting.

We showed that spirometric values improve in most patients after tracheal stenting; however, a few of our patients showed no or only minimal improvement. Since there were significant correlations between the increase in the minimum tracheal CSA and the increase in spirometric values between pre- and poststenting examinations, one reason that patients did not experience improvement could be insufficient expansion of the tracheal stent, probably caused by a rigid thoracic malignancy. Other possible explanations for limited improvement in spirometry include shifting of the choke-point to a different, weaker segment of the central airway that was not covered by the stent; turbulent airflow caused by the implanted stent; restricted expectoration due to the stent; and insufficient poststenting spirometry due to stent-induced airway irritation. These secondary stent-related conditions could be related to the observed weak correlation between tracheal CSA measurements and the spirometric values at the poststenting examination, compared with the stronger correlations observed at the prestenting examination. These hypotheses should be evaluated in future studies.

Although the majority (81\%) of enrolled patients in our study were current or ex-smokers, we did not find a significant correlation between LAA\% and pre- or poststenting spirometric values. Compared with previous publications analyzing COPD patients and smokers that demonstrated significant correlations between LAA\% and spirometric values [25] [26], the discordant observations of our study may suggest that, in patients with malignant tracheal stenosis, the severity of the tracheal stenosis is the most important factor for reduced airflow limitation, and the extent of emphysema may be an inferior, lesser factor. This may be partially supported by the observation that the correlation coefficients between LAA\% and the spirometric values increase after stenting, although the correlations are not significant. The true contribution of tracheal stenosis and emphysema severity should be rigorously evaluated in future studies with sufficient numbers of patients.

Although in this study we evaluated correlations between CT-based tracheal measurement and spirometric values only, we have also applied several different modalities in patients with airway/obstructive diseases, such as stereoscopic bronchoscopy and vibration response imaging [27] [28]. The combination of CT-based tracheal measurement and these new advanced modalities would provide further physiological insight into abnormal narrowing of the central airways in near future. Also, rigorous assessments using both chest CT and bronchoscopy in order to observe morphological and dynamic (ventilatory) features of tracheal stenosis may bring further knowledge to comprehend true abnormalities at the point of malignant tracheal stenosis.

There are several important limitations to our study. First, the total number of patients was small, particularly for the poststenting analysis, and the number of 
analyzed patients was different at pretreatment and posttreatment examinations. Second, we included various types of malignant tracheal stenosis such as direct invasion by lung cancer and external compression by lymph node metastases. Ideally, these various causes of tracheal stenoses would be categorized into subgroups; however, subgroup analysis was not feasible in our small study. Third, since different types of tracheal stents were used, we cannot deny the influence of the type of stent or stent matrix on posttreatment tracheal CSA measurement. Although we confirmed that severe metallic artifacts did not exist on poststenting CT, the reliability of poststenting tracheal CSA measurements should be examined in a future study with a larger number of patients. Fourth, we did not evaluate the long-term outcomes of tracheal stenting. Since it is already known that the stent occasionally causes another airway stenosis around its peripheral edge, it may be insufficient to evaluate posttreatment CT and spirometry immediately after stenting without further follow-up. Fifth, we did not evaluate expiratory CT. It has been reported that the expiratory minimum tracheal CSA strongly correlates with spirometric values in patients with RP [17]. We may have found stronger correlations between tracheal CSA and spirometric values if expiratory CT images had been available. Sixth, the CT scanners and protocols were not standardized. Tracheal measurements should be robust, even with different CT settings, but the LAA\% measurement is more sensitive and more easily influenced by unstandardized CT protocols.

In conclusion, the tracheal CSA measured on chest CT significantly correlates with spirometric values, particularly at prestenting examination, and an increase in the minimum tracheal CSA weakly correlates with an improvement in spirometric values after stenting. These observations can be expanded as clinical predictors of lung function in patients with malignant tracheal stenosis.

\section{Conflicts of Interest}

All authors do not have any conflicts of interest to disclose.

\section{References}

[1] Luomanen, R.K.J. and Watson, W.L. (1968) Autopsy Findings. In: Watson, L., Ed., Lung Cancer. A Study of Five Thousand Memorial Hospital Cases, Mosby, Co., St. Louis, 504-510.

[2] Brouns, M., Jayaraju, S.T., Lacor, C., De Mey, J., Noppen, M., Vincken, W. and Verbanck, S. (2007) Tracheal Stenosis: A Flow Dynamics Study. Journal of Applied Physiology, 102, 1178-1184. https://doi.org/10.1152/japplphysiol.01063.2006

[3] Nishine, H., Hiramoto, T., Kida H., Matsuoka, S., Mineshita, M., Kurimoto, N. and Miyazawa, T. (2012) Assessing the Site of Maximal Obstruction in the Trachea Using Lateral Pressure Measurement during Bronchoscopy. American Journal of Respiratory and Critical Care Medicine, 185, 24-33. https://doi.org/10.1164/rccm.201104-0701OC

[4] Ernst, A., Feller-Kopman, D., Becker, H.D. and Mehta, A.C. (2004) Central Airway Obstruction. American Journal of Respiratory and Critical Care Medicine, 169, 1278-1297. https://doi.org/10.1164/rccm.200210-1181SO 
[5] Razi, S.S., Lebovics, R.S., Schwartz, G., Sancheti, M., Belsley, S., Connery, C.P. and Bhora, F.Y. (2010) Timely Airway Stenting Improves Survival in Patients with Malignant Central Airway Obstruction. The Annals of Thoracic Surgery, 90, 10881093. https://doi.org/10.1016/j.athoracsur.2010.06.093

[6] Williamson, J.P., Phillips, M.J., Hillman, D.R. and Eastwood, P.R. (2010) Managing Obstruction of the Central Airways. Internal Medicine Journal, 40, 399-410.

https://doi.org/10.1111/j.1445-5994.2009.02113.x

[7] Miyazawa, T. and Arita, K. (1998) Airway Stenting in Japan. Respirology, 3, 229234. https://doi.org/10.1111/j.1440-1843.1998.tb00127.x

[8] Miyazawa, T., Yamakido, M., Ikeda, S., Furukawa, K., Takiguchi, Y., Tada, H. and Shirakusa, T. (2000) Implantation of Ultraflex Nitinol Stents in Malignant Tracheobronchial Stenosis. Chest, 118, 959-965. https://doi.org/10.1378/chest.118.4.959

[9] Serrano, C., Laborda, A., Lozano, J.M., Caballero, H., Sebastián, A., Lopera, J. and de Gregorio, M.A. (2013) Metallic stents for Tracheobronchial Pathology Treatment. Cardio Vascular and Interventional Radiology, 36, 1614-1623. https://doi.org/10.1007/s00270-013-0602-6

[10] Mehta, A.C. (2008) AERO Self-Expanding Hybrid Stent for Airway Stenosis. Expert Review of Medical Devices, 5, 553-557. https://doi.org/10.1586/17434440.5.5.553

[11] Miyazawa, T., Miyazu, Y., Iwamoto, Y., Ishida, A., Kanoh, K., Sumiyoshi, H., Doi, M. and Kurimoto, N. (2004) Stenting at the Flow-Limiting Segment in Tracheobronchial Stenosis Due to Lung Cancer. American Journal of Respiratory and Critical Care Medicine, 169, 1096-1102. https://doi.org/10.1164/rccm.200312-1784OC

[12] Miller, R.D. and Hyatt, R.E. (1973) Evaluation of Obstructing Lesions of the Trachea and Larynx by Flow-Volume Loops. American Review of Respiratory Disease, 108, 475-481.

[13] Rotman, H.H., Liss, H.P. and Weg, J.G. (1975) Diagnosis of Upper Airway Obstruction by Pulmonary Function Testing. Chest, 68, 796-799.

https://doi.org/10.1378/chest.68.6.796

[14] Vergnon, J.M., Costes, F., Bayon, M.C. and Emonot, A. (1995) Efficacy of Tracheal and Bronchial Stent Placement on Respiratory Functional Tests. Chest, 107, 741746. https://doi.org/10.1378/chest.107.3.741

[15] Acres, J.C. and Kryger, M.H. (1981) Clinical Significance of Pulmonary Function Tests: Upper Airway Obstruction. Chest, 80, 207-211. https://doi.org/10.1378/chest.80.2.207

[16] Hyatt, R.E. and Black, L.F. (1973) The Flow-Volume Curve: A Current Perspective. American Review of Respiratory Disease, 107, 191-199.

[17] Usuba, A., Yamashiro, T., Handa, H., Matsuoka, S., Yamano, Y., Mineshita, M. and Miyazawa, T. (2015) Quantitative Computed Tomography Measurement of Tracheal Cross-Sectional Areas in Relapsing Polychondritis: Correlations with Spirometric Values. Respiration, 90, 468-473. https://doi.org/10.1159/000441303

[18] Matsuoka, S., Kurihara, Y., Yagihashi, K., Hoshino, M. and Nakajima, Y. (2008) Airway Dimensions at Inspiratory and Expiratory Multisection CT in Chronic Obstructive Pulmonary Disease: Correlation with Airflow Limitation. Radiology, 248, 1042-1049. https://doi.org/10.1148/radiol.2491071650

[19] Yamashiro, T., San Jose Estepar, R., Matsuoka, S., Bartholmai, B.J., Ross, J.C., Diaz, A., Murayama, S., Silverman, E.K., Hatabu, H. and Washko, G.R. (2011) Intrathoracic Tracheal Volume and Collapsibility on Inspiratory and End-Expiratory CT Scans Correlations with Lung Volume and Pulmonary Function in 85 Smokers. Academic Radiology, 18, 299-305. https://doi.org/10.1016/j.acra.2010.11.005 
[20] Ederle, J.R., Heussel, C.P., Hast, J., Fischer, B., Van Beek, E.J., Ley, S., Thelen, M. and Kauczor, H.U. (2003) Evaluation of Changes in Central Airway Dimensions, Lung Area and Mean Lung Density at Paired Inspiratory/Expiratory High-Resolution Computed Tomography. European Radiology, 13, 2454-2461. https://doi.org/10.1007/s00330-003-1909-5

[21] Koyama, H., Ohno, Y., Yamazaki, Y., Onishi, Y., Takenaka, D., Yoshikawa, T., Nishio, M., Matsumoto, S., Murase, K., Nishimura, Y. and Sugimura, K. (2012) Quantitative Bronchial Luminal Volumetric Assessment of Pulmonary Function Loss by Thin-Section MDCT in Pulmonary Emphysema Patients. European Journal of Radiology, 81, 384-388. https://doi.org/10.1016/j.ejrad.2010.12.042

[22] Miller, M.R., Hankinson, J., Brusasco, V., Burgos, F., Casaburi, R., Coates, A., Crapo, R., Enright, P., van der Grinten, C.P., Gustafsson, P., Jensen, R., Johnson, D.C., MacIntyre, N., McKay, R., Navajas, D., Pedersen, O.F., Pellegrino, R., Viegi, G. and Wanger, J. (2005) ATS/ERS Task Force: Standardization of Spirometry. European Respiratory Journal, 26, 319-338. https://doi.org/10.1183/09031936.05.00034805

[23] Handa, H., Miyazawa, T., Murgu, S.D., Nishine, H., Kurimoto, N., Huang, J. and Colt, H.G. (2012) Novel Multimodality Imaging and Physiologic Assessments Clarify Choke-Point Physiology and Airway Wall Structure in Expiratory Central Airway Collapse. Respiratory Care, 57, 634-641.

[24] Handa, H., Huang, J., Murgu, S.D., Mineshita, M., Kurimoto, N., Colt, H.G. and Miyazawa, T. (2014) Assessment of Central Airway Obstruction Using Impulse Oscillometry before and after Interventional Bronchoscopy. Respiratory Care, 59, 231 240. https://doi.org/10.4187/respcare.02094

[25] Sakai, N., Mishima, M., Nishimura, K., Itoh, H. and Kuno, K. (1994) An Automated Method to Assess the Distribution of Low Attenuation Areas on Chest CT Scans in Chronic Pulmonary Emphysema Patients. Chest, 106, 1319-1325. https://doi.org/10.1378/chest.106.5.1319

[26] Yamashiro, T., Moriya, H., Tsubakimoto, M., Matsuoka, S. and Murayama, S. (2016) Continuous Quantitative Measurement of the Proximal Airway Dimensions and Lung Density on Four-Dimensional Dynamic-Ventilation CT in Smokers. International Journal of Chronic Obstructive Pulmonary Disease, 11, 755-764. https://doi.org/10.2147/COPD.S100658

[27] Miyazawa, T., Nobuyama, S., Nishine, H., Handa, H. and Mineshita, M. (2006) Choke Point Physiology in Airway Stenting: A Case Presentation and Discussion. Respiratory Investigation, 54, 237-240. https://doi.org/10.1016/j.resinv.2016.02.006

[28] Mineshita, M., Kida, H., Handa, H., Nishine, H., Furuya, N., Inoue, T., Matsuoka, S. and Miyazawa, T. (2016) Regional Lung Sound Asynchrony in Chronic Obstructive Pulmonary Disease Patients. Respiration, 92, 252-257.

https://doi.org/10.1159/000449255 
Submit or recommend next manuscript to SCIRP and we will provide best service for you:

Accepting pre-submission inquiries through Email, Facebook, LinkedIn, Twitter, etc. A wide selection of journals (inclusive of 9 subjects, more than 200 journals)

Providing 24-hour high-quality service

User-friendly online submission system

Fair and swift peer-review system

Efficient typesetting and proofreading procedure

Display of the result of downloads and visits, as well as the number of cited articles Maximum dissemination of your research work

Submit your manuscript at: http://papersubmission.scirp.org/

Or contact ojmi@scirp.org 